\title{
Hardening of Steel Perforated Tape by Nd:YAG Laser
}

\section{Viktors Mironovs ${ }^{1,} \mathrm{a}$, Mihails Lisicins ${ }^{1, b^{*}}$, Pavels Onufrijevs ${ }^{2, c}$,} Faina Muktepavela ${ }^{3, d}$ and Arturs Medvids ${ }^{2, e}$

${ }^{1}$ Scientific Laboratory of Powder Materials, Riga Technical University, Azenes str. 16/20-331, Riga, LV-1048, Latvia

\author{
2 Institute of Technical Physics, Faculty of Materials Science and Applied Chemistry, \\ Riga Technical University, P. Valdena str. 3/7, Riga, LV-1048, Latvia \\ ${ }^{3}$ Institute of Solid State Physics, University of Latvia, Kengaraga str.8, Riga, LV-1063, Latvia \\ aviktors.mironovs@rtu.lv, ${ }^{b}$ mihails.lisicins@rtu.lv, ${ }^{c}$ onufrijevs@latnet.Iv, dfamuk@latnet.Iv, \\ emedvids@latnet.lv
}

Keywords: Laser, Hardening, Steel, Perforated Tape

\begin{abstract}
One of the directions of application of the perforated metal material is their use as cutting elements in the production of processing tools. In this case it is necessary to carry out hardening of cutting surfaces to increase their hardness. One of the methods of hardening metals could be laser treatment. Therefore, the present work is a study of the effect of Nd:YAG laser radiation on the microstructure and hardness of fragments formed from steel perforated tape. Different laser scan speeds (doses) were used in the experiments. The results have shown that the increase the microhardness of 30-40\% after the laser treatment of steel perforated tape in the surface layer in a depth range up to $1 \mu \mathrm{m}$ take place. The studies of microstructure of fragments formed from steel perforated tape have shown the reduction of the structure size and the presence of thin colour oxide layers, which is consistent with the results on nanoindentation. Hardening of the metal by laser radiation is carried out without surface melting which eliminates the change of macroroughness and the need for subsequent machining process.
\end{abstract}

\section{Introduction}

Perforated metal materials (PMM) have wide application in the manufacture of products from small and medium-carbon steels. One of the new areas of PMM application can be their use as cutting elements in the manufacture of machining tools [1-2]. Such tools can be used in construction for finishing works in wood, textile and other industries. In order to form a cutting profile (teeth) the tape is cut longitudinally along the perforation holes (Fig.1). In this case the step of teeth corresponds to the step of perforation holes. The shape of the teeth depends on the type of perforations and a cut direction of the perforated strip (Fig.2).

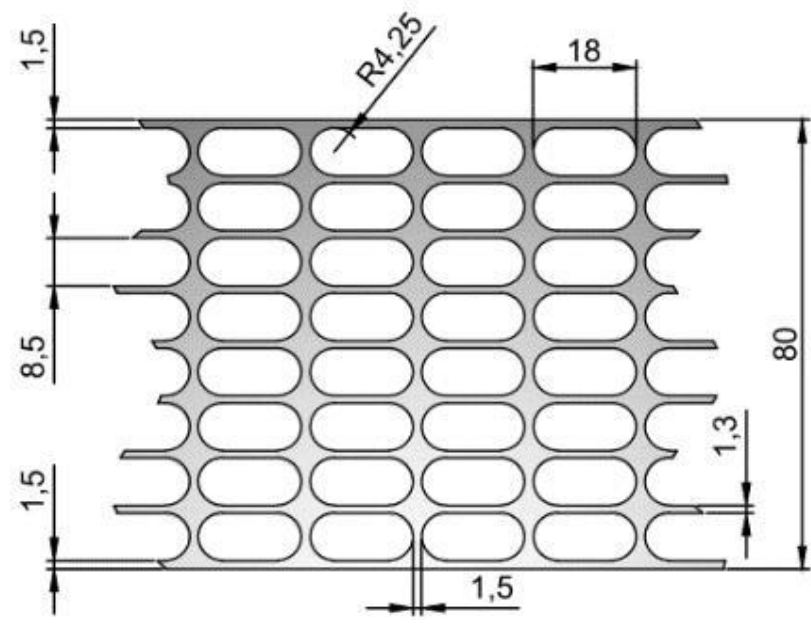

Fig.1. Perforated metal materials - PST-1

The cutting teeth are sharpened by the lengthwise of tape at an angle $\alpha$ (Fig.2a) or by the thickness at an angle $\beta$ (Fig.2b) depending on the direction of movement of the working tool [3]. 


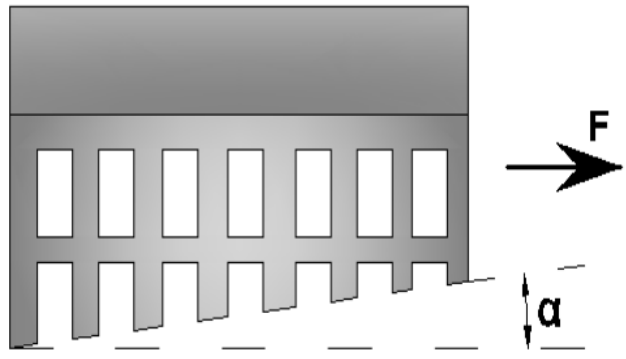

a)

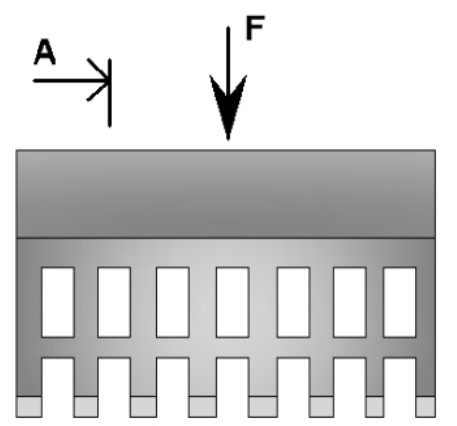

$\stackrel{A}{\longrightarrow}$
A-A

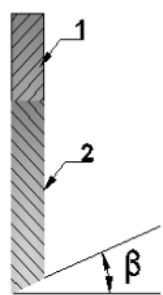

b)

Fig. 2. The formation of cutting teeth by the lengthwise (a) and by the thickness (b) of tape

It has been established that it is appropriate to form a comb-shaped tool, which consists of a body and the unit of parallel plates of PMM with preformed teeth (Fig.3).

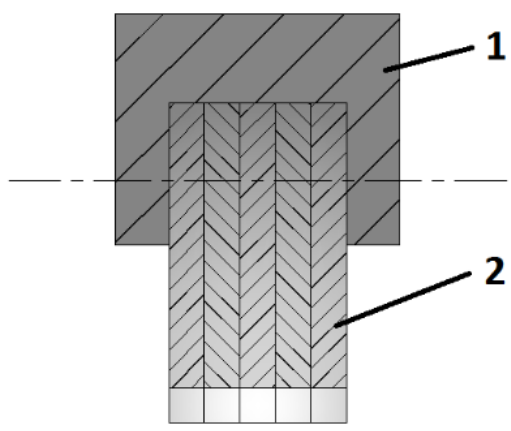

a)

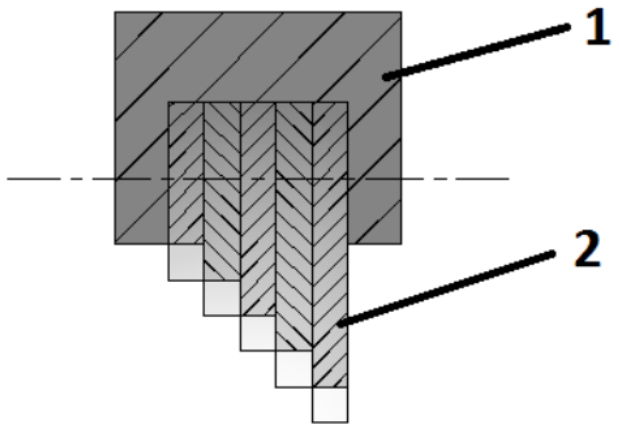

b)

Fig. 3. Cross-section of comb-shaped tool with the unit of parallel plates: similar (a) or different (b) height. 1- body; 2- unit of parallel plates

Plates formed from PMM may be assemble in the block by welding or by filling the polymer through the perforations holes (Fig.4 a) or in the tube (Fig. 4 b).

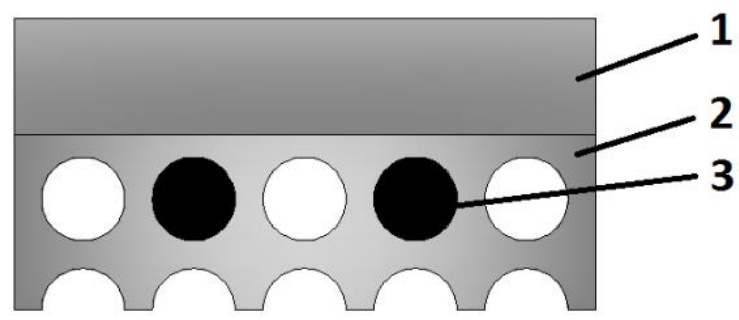

a)

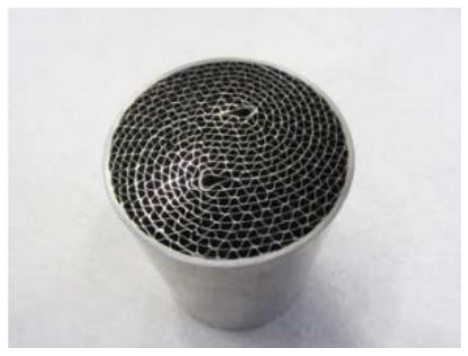

b)

Fig. 4. Fastening plates in the block by the polymer (a) and in the tube tubular shell (b)

Constructive and microgeometrical schemes of devices discussed above suggest the possibility of using perforated steel scrap for cutting tools. However, the use a starting material for other purposes, in this case for the cutting edge, requires a significant hardening of the surface layer. There is various methods by which localized hardening can be accomplished. One method could be laser processing, which in contrast to the known processes of heat strengthening (bulk quenching of high-frequency currents, electric heating and etc) is not bulk but the local, superficial process, without change of surface both macro and microgeometry [4-9]. Laser hardening consists of the rapid heating of material surface by laser beam and intensive cooling due to the thermal conductivity of metals. This process causes a fine grained structure formation in the thin layer on 
the surface of the part. Laser hardening increases hardness and wear resistance [4,5]. In the present work the effect of laser exposure modes on the microstructure and hardness of steel perforated tape has been investigated.

\section{Experimental and Methods}

Steel Perforated Tapes with thickness 1.2 (Table 1) were used for the study.

Table 1. Properties of steel perforated tape

\begin{tabular}{|c|c|c|c|c|c|}
\hline Designation & $\begin{array}{c}\text { Thickness } \\
{[\mathrm{mm}]}\end{array}$ & $\begin{array}{c}\text { Perforation } \\
\text { ratio [\%] }\end{array}$ & $\begin{array}{c}\text { Effective cross- } \\
\text { section, }\left[\mathrm{mm}^{2}\right]\end{array}$ & $\begin{array}{c}\text { Carbon content } \\
{[\%]}\end{array}$ & Standard \\
\hline PST-1 & 1.20 & 70.50 & 14.44 & 0.50 & DIN EN 10132 \\
\hline
\end{tabular}

The steel samples from perforated tape $1.20 \mathrm{~mm}$ thick were irradiated by pulsed Nd:YAG laser with following parameters: $\lambda=1064 \mathrm{~nm}, \tau=6 \mathrm{~ns}, \mathrm{I}=104.2 \mathrm{MW} / \mathrm{cm}^{2}$, scanning speed $\mathrm{v}=30 \mu \mathrm{m} / \mathrm{s}$. To evaluate the effect of laser radiation on the surface layer hardness $(\mathrm{H})$ values by methods of microand nanoindentation were investigated. Microhardness test use Vickers diamond pyramid with square base indenter under lower loads ( $1 \mathrm{~g}$ to $100 \mathrm{~g}$ ). Microhardness values (HV) were obtained using advanced static loading device on the instrument PMT-3M. For nanoindentation (depths less than $0.2 \mu \mathrm{m}$ ) the nanotester MTS Nano G200 with Berkovich diamond pyramid with triangular base indenter tip (radius $<20 \mathrm{~nm}$ ) was used for direct continuous loading and displacement registration. The nanoindentation data obtained allow not only hardness $(\mathrm{H})$ but also Young's modulus $(\mathrm{E})$ to be derived. The loading-unloading curve also provides information about plastic deformation in a more general way. Microstructures of the surface layers were investigated using optical microscopy (Nikon ECLIPSE L150).

\section{Results and Discussion}

Microstructure studies have shown refinement of the ferrite and pearlite structures in steel and the presence of a thin oxide films on the surface (Fig. 5).

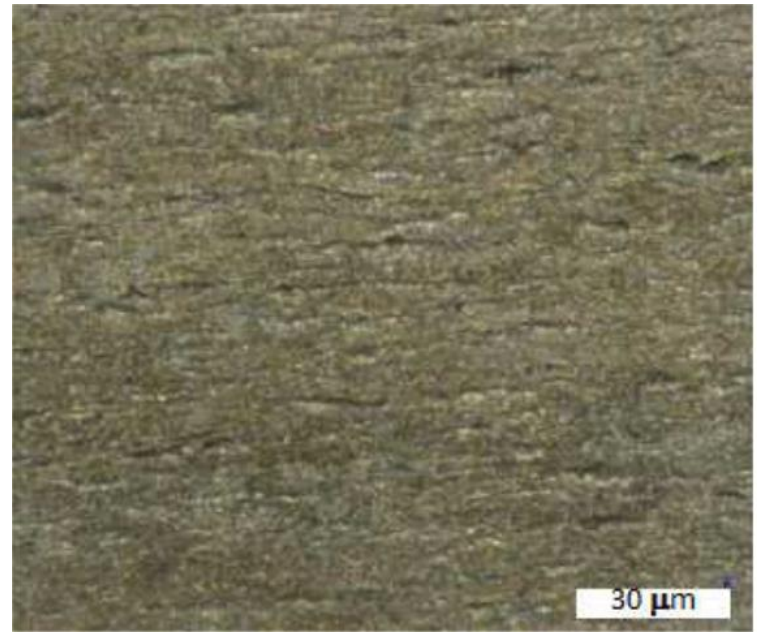

a)

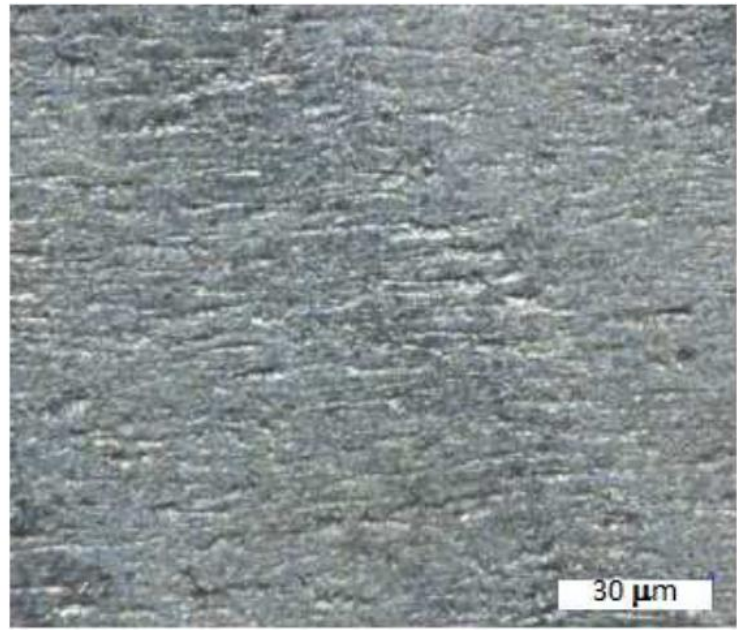

b)

Fig. 5. Micrographs of PST-1 samples (a) non-irradiated and (b) the irradiated surface at intensity $\mathrm{I}=104.2 \mathrm{MW} / \mathrm{cm}^{2}$ and scanning speed $\mathrm{v}=30 \mu \mathrm{m} / \mathrm{s}$ 
Mechanical behaviour of steel surface (steel tapes with carbon content $0.50 \%$ ) after laser treatment was investigated firstly by traditional microhardness test. Results of microhardness $(\mathrm{H})$ measurements at different loads $(\mathrm{P}, \mathrm{g})$ both for initial state of PST-1 and for sample after laser treatment are presented in Table 2.

Table 2. The values of microhardness $(\mathrm{H})$ measured at different loads $(\mathrm{P}, \mathrm{g})$

\begin{tabular}{|c|c|c|}
\hline $\mathrm{P},[\mathrm{g}]$ & $\mathrm{h}$ (indentation depth), $[\mu \mathrm{m}]$ & $\mathrm{H},[\mathrm{GPa}]$ \\
\hline \multicolumn{2}{|l|}{ Non-irradiated } \\
\hline 100 & 4.70 & 1.66 \\
\hline 20 & 2.40 & 1.69 \\
\hline 10 & 1.50 & 1.68 \\
\hline \multicolumn{2}{|c|}{ After laser treatment } \\
\hline 100 & 5.00 & 1.48 \\
\hline 20 & 2.04 & 1.82 \\
\hline 10 & 1.23 & 2.49 \\
\hline
\end{tabular}

Investigations showed that after the laser treatment the microhardness increase from 1.68 to 2.50 $\mathrm{GPa}$ in the surface layer of $1 \mu \mathrm{m}$ occurs. The effect is $48 \%$. At the same time decrease of microhardness in depth of $\mathrm{h}=5 \mu \mathrm{m}$ compared with initial state is observed. This may be due to the spread of the heating zone in this depth and the reduction of the initial machining influence.

To investigate the more of the surface layers, less than 1 micron, nanohardness measurement have been conducted. Average data of hardness (H) and elastic modulus (E) for investigated steel samples with carbon content $0.50 \%$ untreated and after laser treatment in Fig.6a and $6 \mathrm{~b}$ are presented. Here "Untreated "-initial state of sample, "Triangle -shaped"- sample after laser treatment.

As can be seen laser irradiation leads to hardness increases to a value $5 \mathrm{GPa}$ especially in the surface layers. At depth of $h=50 \mathrm{~nm}$ the effect is $66 \%$, however, at a depth of $100 \mathrm{~nm}(0.1 \mu \mathrm{m})$ the effect is reduced to $45 \%$. High strengthening effect in the thin surface layer may be associated with the influence of oxide phases. The presence of oxides phases after laser treatment was by studies detected. It should be noted that the measurement nanohardness is greatly influenced the structural heterogeneity and the surface roughness. Despite this, the coincidence of the average results of nanohardness with microhardness values allows us to conclude of a significant laser hardening of steel samples with carbon content $0.50 \%$ in the surface layer $<1-2 \mu \mathrm{m}$.

According nanoindentation in the layer of $<1 \mu \mathrm{m}$ a small decrease in Young's modulus from 210 GPa to $190 \mathrm{GPa}$ was observed that indicates change of structural and chemistry PST-1 surface state after laser irradiation. The laser-induced appearance of point defects and dislocations or new oxides phases in combination with a fine structure in surface layer can lead to the hardening effect.

Hardening effect obtained in this work cannot be associated to carbide phases formation, because, unlike [8,9] we have not used a $\mathrm{CO}_{2}$ laser but solid state Nd:YAG laser. The obtained hardness values are also not connected with laser-induced martensitic transformation [4-7] which is characterized by higher values of hardness $(\mathrm{H}>6 \mathrm{GPa})$ and the specific microstructure and relief formation, that was not observed. In the same time formation of fine grained structure and oxide phases in the surface layer under Nd:YAG laser treatment is a reasonable explanation for the resulting effect [5]. Relatively high hardness without cracking at indentation gives reason to develop the laser hardening technology for steel perforated tapes. 

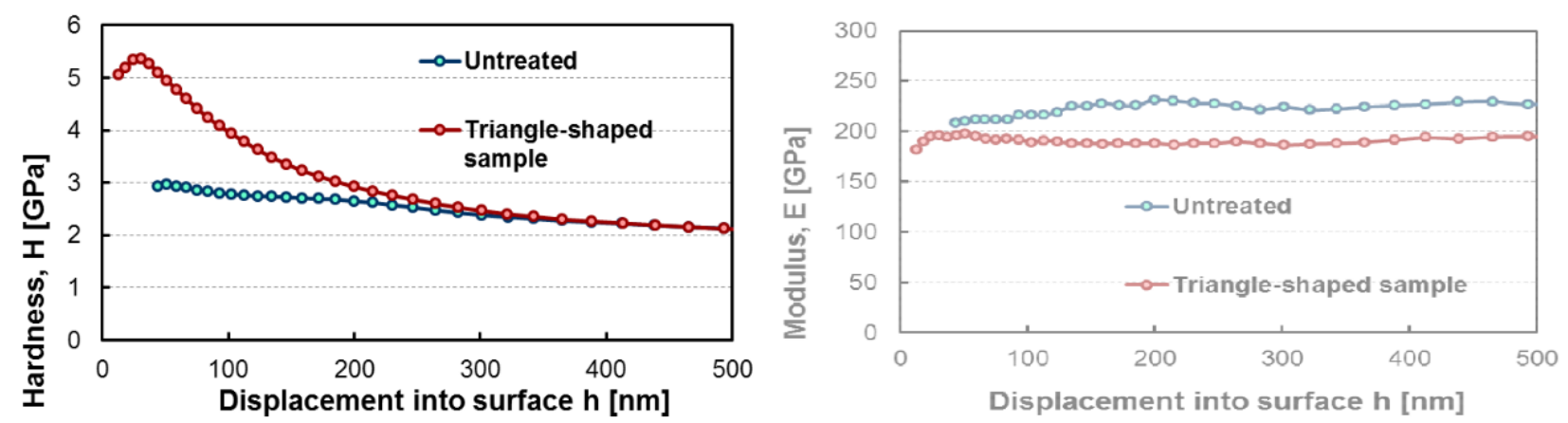

Fig. 6. Hardness (a) un elastic modulus (b) in dependence on the indentation depth (h) for initial state of PST-1 surfaces and after laser treatment

\section{Summary}

The work shows that laser treatment leads to the hardness increase by $66 \%$ in surface layer of 0.1 $\mu \mathrm{m}$ and by $48 \%$ in layer of $1 \mu \mathrm{m}$. The effect falls off at a depth of $>1-2 \mu \mathrm{m}$. Changes in the microstructure with conservation of surface macrorelief are detected. Hardness data is consistent with the results of microstructure and elastic modulus data. This allows to state that steel perforated tapes treated by laser radiation can be used to manufacture elements for cutting for tools.

\section{References}

[1] V. Mironovs, M. Lisicins, Perforated metal materials and their application possibilities, Riga Technical University Publishing House, Riga, Latvia, 2015 (in Latvian).

[2] V. Mironovs, M. Lisicins, I. Boiko, V. Zemchenkovs, Manufacturing of Cellular Structures of the Perforated Steel Tape, Proceedings of the $8^{\text {th }}$ International Conference of DAAAM Baltic Industrial Engineering, Otto T. (ed.), Estonia, Tallinn: Tallinn University of Technology (2012) 688 $-693$.

[3] V. Mironovs, M. Lisicins, V. Zemcenkovs, A. Urbahs, Patent of Republic of Latvia Nr. LV 14988 B, Comb type tool and its manufacturing method, Riga Technical University, Riga, Latvia (2014)

[4] M. F. Ashby et al. Acta Met. Volume 32, Issue 11 (1984) 46 - 49.

[5] Konsido, Sun D.K., Le Y.P, A fundamental study of laser transformation hardening, Met. Trans A.14. Volume 6, Issue 1 (1983) 643 - 653.

[6] P.W. Chan, The reflectivity of metals of high temperatures heated by pulses laser, Physics letters, Volume 61a, Issue 3 (1974) 151 - 154.

[7] G. H. Harth, V. G. Gregson, Laser heat treating of steels, Metals, Volume 28, Issue 4 (1976) 30 -34 .

[8] H. Kwasumi, Metal surface hardening CO2-laser, Technokrat, Volume 11, Issue 6 (1978) 11 - 20

[9] J. F. Ready, Change of reflectivity of metallic surface during irradiation by C02-TEA-Iazer pulses, J. Quant .Electr. N2 (1976) 137 - 145. 